\title{
NOVEDADES VELAZQUEÑAS
}

\author{
POR \\ ALFONSO E. PÉREZ SÁNCHEZ \\ Universidad Complutense de Madrid
}

In the following study are presented various paintings which are attributed - with some certainty - to Velázquez and that belong to different stages of his production. Within them, it has special significance the identification of the funeral portrait of the beato Simón de Rojas, painted in 1624 .

We argue, as well, the rejection of the attribution of one Immaculate, once pretended to be ascribed to Velázquez, and that is, in fact, a work by Alonso Cano.

La ocasión que brinda la celebración del cuarto centenario del nacimiento del maestro sevillano, al que se dedica este número de Archivo Español de Arte, debe ser ä́provechada para estudiar y poner en circulación algunas obras que quizás deban asociarse a su nombre y, a la vez, razonar por qué algunas que han pretendido, en los últimos años, acogerse a tan brillante atribución deben considerarse definitivamente ajenas a su pincel.

En ocasión de la publicación en castellano del clásico libro de Justi, Velázquez y su siglo, en el ya remoto 1953, Gaya Nuño incluyó un brillante y extenso ensayo en el que recogía lo que la investigación y la bibliografía posterior el gran libro habían ido aportando, especialmente en cuanto a obras del maestro o a él atribuidas.

Quizás valiera Ia pena hacer algo parecido partiendo de los Catálogos más recientes, los de Gudiol (2. ${ }^{a}$ ed. 1982) y López Rey (1963, ed. actualizada 1997) así como de algunas atribuciones que han circulado por el mercado y aún por ciertas publicaciones más o menos prestigiosas, en los últimos años. No es posible, en un artículo que no puede ser demasiado extenso, cumplir tan ambicioso propósito pero sí vale la pena, al menos, comentar algunas piezas destacadas, y dar a conocer otras que creo merecen consideración.

Novedad importante ha constituido la presentación en la Exposición de Sevilla ${ }^{1}$ de un soberbio ejemplar de la composición bien conocida por varios ejemplares citados y a veces reproducidos desde antiguo, del San Pedro en Lágrimas que ha pasado por diversas atribuciones, ninguna de las cuales lograba, en realidad, convencer. El ejemplar que fue de Beruete y luego de la colección Heineman de Nueva York y hoy se encuentra en el comercio, se había considerado siempre como el de mejor calidad, y Aureliano de Beruete - su propietario- lo atribuyó decididamente a Velázquez ${ }^{2}$ seguido en ello por Mayer, pero sin que su propuesta fuese aceptada por otros críticos posteriores.

1 Velázquez en Sevilla. Catálogo. Sevilla, 1999, n. 92.

2 Aureliano de Beruete. Velázquez. París, 1998 (ed. española 1989). 
Atribuciones a Zurbarán apuntadas por Allende Salazar ${ }^{3}$ (1925) y por Camón Aznar (1964) ${ }^{4}$ han sido unanimente rechazadas, y la de Herrera el Viejo que Martinez Ripoll parece aceptar para la invención de la composición ${ }^{5}$, - aunque no reconozca como de su mano ninguna de las versiones conocidas-, no parece tampoco convincente.

La existencia de un crecido número de ejemplares de calidades muy desiguales y con ligerísimas variantes en el fondo obligaban a pensar en la existencia de un modelo o prototipo importante, que hubo de ser estimado en la Sevilla del primer tercio del siglo XVII ${ }^{6}$.

Al citado de Beruete y Heineman (Fig. 2) se añaden el de la colección Millán Delgado, el del Marqués de Villar del Tajo (Fig. 3), el que conserva la Hermandad de los Panaderos (Fig. 4), otro en el pueblo de la Algaba (Sevilla) y el del Museo de Bellas Artes de Sevilla. Este último, donado al Museo por González Abreu en 1928, ha sido considerado (Hernández Díaz, 1967) obra de Herrera, pero más recientemente se ha atribuido, inexplicablemente, a Juan del Castillo ${ }^{7}$. Se puede añadir otro que perteneció a D. J.M. Gómez Flores y que según López Rey procedía de un convento de la Puebla de Montalban, y otro, conocido solo por deficiente fotografía, que pertenecía, después de la guerra civil, a un particular madrileño. (Fig. 5).

Todos ellos derivan con evidencia de un modelo común y solo pequeños detalles en el fondo de paisaje, ciertos pormenores del plegado de las telas o de la posición de las llaves, les distinguen, aparte, claro está, de la factura y la considerable diferencia de calidad.

La aparición del ejemplar que se ha exhibido en la Exposición sevillana parece resolver de modo, que creemos definitivo, el problema, pues se trata del ejemplar de más alta calidad y de más intensa concentración expresiva (Fig. 1).

Como ha señalado Manuela Mena en la correspondiente ficha del Catálogo, la hermandad técnica con obras como el San Juan Evangelista o la Inmaculada de la National Gallery, es manifiesta, y la radiografía ha evicenciado modificaciones de la silueta que sólo el «inventor» de la composición puede haber hecho.

La monumental solidez de la figura, el enérgico tratamiento de la anatomía en manos y pies, que enlaza sin dificultad con el que Ribera da a sus personajes en la etapa juvenil, que hubo de ser decisiva para inspirar al joven Velázquez ${ }^{8}$, y la sabia y eficacísima austeridad del paisaje envolvente que contrasta, como ha sugerido Manuela Mena, con la interpretación «lineal y puramente decorativa» de las otras versiones conocidas, copias con toda seguridad, hacen de la obra - fechable hacia 1619, más bien que hacia 1617- una pieza enormemente significativa en la producción juvenil del maestro.

En el texto que Palomino dedica a Velázquez, se dice textualmente, al referirse a sus retratos no oficiales: «También pintó el retráto del V.P.M. Fr. Simón de Roxas estando difunto, varón eximio en letras y virtud» ${ }^{9}$.

El Venerable Padre Maestro - hoy Santo, pues fue ya canonizado- falleció en Madrid en 1624 y fue objeto inmediatamente de amplia veneración, por lo que debieron menudear sus retratos vivo y, como veremos, difunto.

3 Allende Salazar.

4 Camón Aznar, José. Velázquez, Madrid, 1964- ..... p. 247.

5 Martínez Ripoll, Antonio. Francisco de Herrera el Viejo. Sevilla, 1978, p. 176.

- Martínez Ripoll, Antonio, (ob. cit) recoge los citados en diversos lugares, como copias de un perdido original de Herrera, bajo los números: P.a.1; P.a.7; P.a.17; P.a.19; P.a.21; y P.a.23.

7 Rocío Izquierdo y Valme Muñoz, Museo de Bellas Artes de Sevilla. Inventario de Pinturas. Sevilla, 1990 , p. 86.

8 Sobre la, para mí evidente, influencia de las obras juveniles de Ribera sobre el joven Velázquez sevillano, no se ha insistido lo suficiente en estos años, y la exposición de Sevilla ha perdido la ocasión de mostrarla.

9 Palomino. Museo Pictórico y Escala Optica. ed. Aguilar, 1947. 


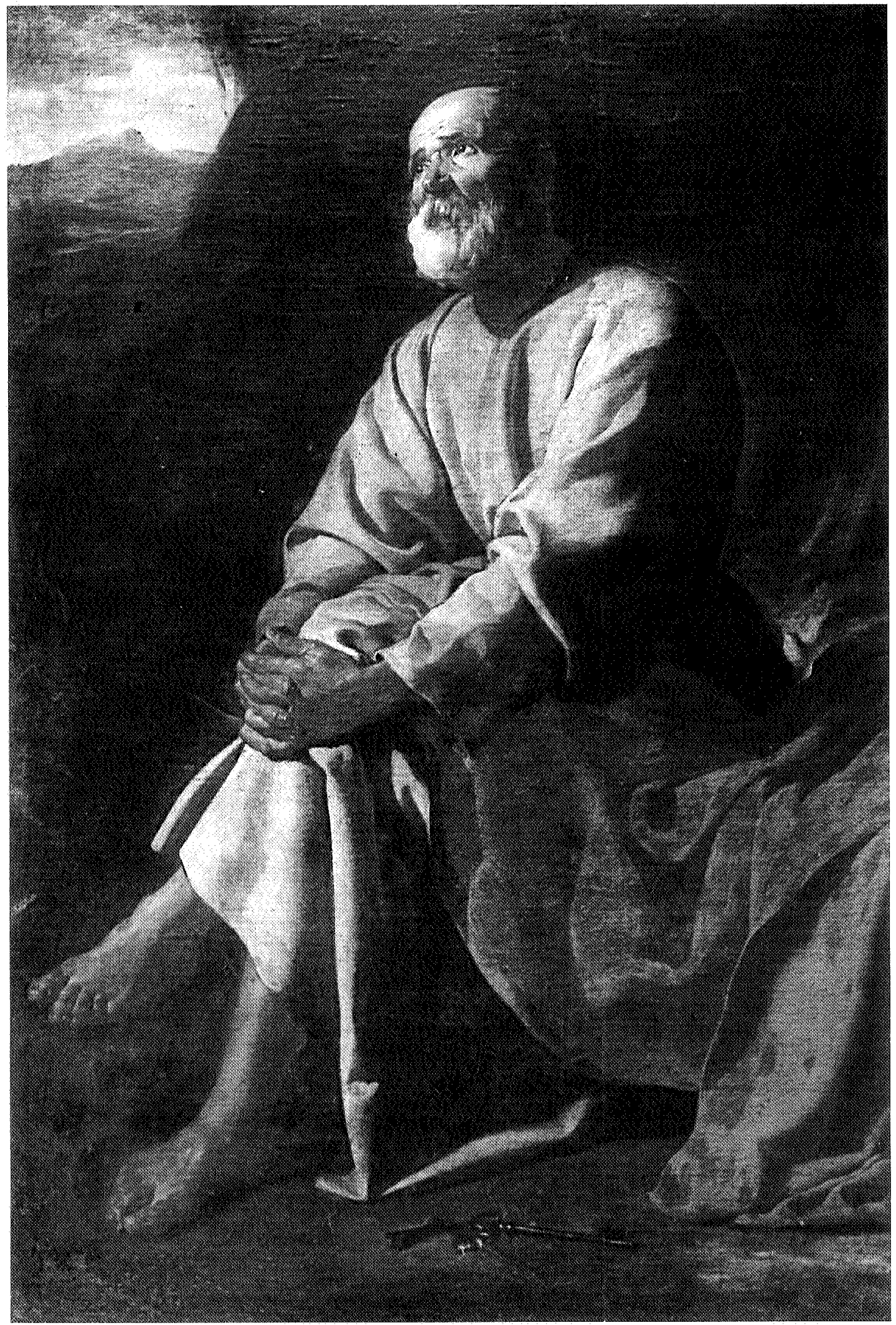

Figura 1. Velázquez. San Pedro en lágrimas. Col. particular. 

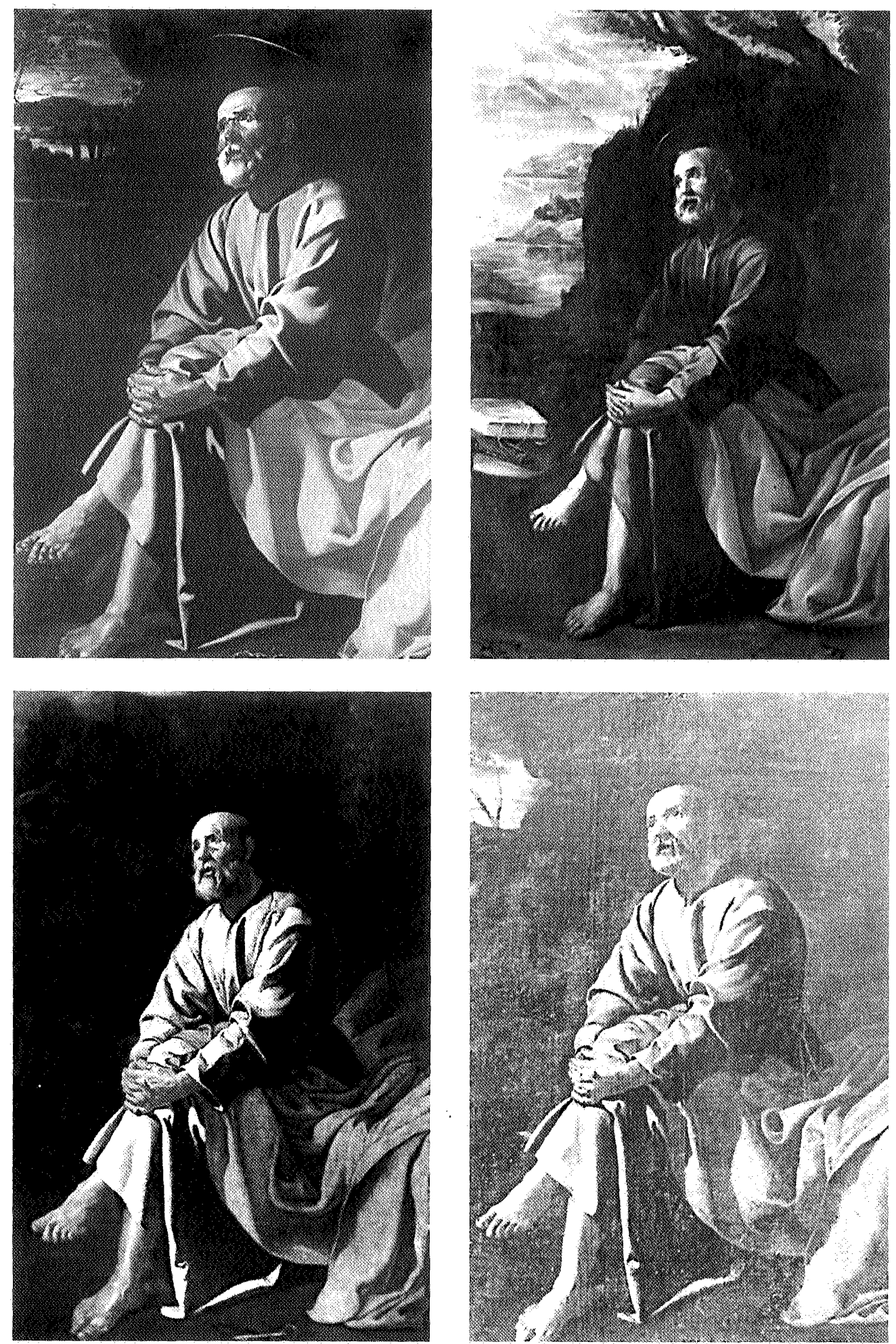

Figura 2. Copia de Velázquez. San Pedro en lágrimas. Antigua col. Beruete.

Figura 3. Copia de Velázquez. San Pedro en lágrimas. Col. Marqués de Villar del Tajo.

Figura 4. Copia de Velázquez. San Pedro en lágrimas. Sevilla. Hermandad de los Panaderos.

Figura 5. Copia de Velázquez. San Pedro en lágrimas. Paradero desconocido. 
No se ha identificado hasta ahora de modo fehaciente la existencia del retrato citado e incluso Mayer llegó a dudar de su existencia pensando que Palomino se había confundido con un retrato que, al parecer, se exhibió en la Exposición Ibero Americana de Sevilla en 1929-1930 atribuido a Zurbarán.

No obstante, conozco al menos dos lienzos relacionados con el Santo que llevan vieja atribución a Velázquez pero que no pueden, en modo alguno, considerarse como suyos. Uno, de colección particular madrileña, muestra, efectivamente, al Santo difunto con los ojos cerrados, una estampa de la Virgen y un rosario sobre el pecho, al lado una palma y de su boca parece salir una filactería con la escrita: «Ave María».

Se le muestra solo de busto, desde el lado izquierdo; no se ven las manos y lleva el capillo de los trinitarios sobre el cual se advierten unas rosas dispuestas a modo de corona. (Fig. 6)

Al dorso, sobre una gruesa capa de pintura de impregnación que no parece muy antigua, se lee «Don Diego Velazquez. Año de 1624» en letra quizás del siglo XVIII.

La calidad nada sobresaliente, un tanto dura en el trazado de las sombras y en el seco contorno de las telas, excluye de modo terminante la atribución al maestro. Durante algún tiempo pude pensar que fuese una copia del perdido original pero no me decidí a darlo a conocer.

Otra pintura, sumamente curiosa y de carácter bien distinto, es la que perteneció a la colección del Marqués de la Remisa, en cuyo Catálogo manuscrito, redactado en 1846 por Ceferino Araujo, se describe con absoluta precisión: «27. Escuela española. Cobre. La exhumación del cadáver del Beato Simón de Rojas, original de Don Diego Velázquez, sumamente concluido de manera que parece un cuadro flamenco. Tiene de alto un piê y seis pulgadas y de ancho dos pies y cinco pulgadas».

Hoy en paradero desconocido, se conoce a través de antigua fotografía (Fig. 7). Su dimensión, reducida a nuestro sistema, equivale a 0,420 x 0,67. Se ve en la compleja composición, el ataud del Santo abierto puesto sobre un tablero. Una multitud de personajes le rodean con gesto de asombro, y un revuelo de mariposas blancas flota sobre la cabeza del venerable. Se trataba, pues, de una pintura de escala menuda que no parece encajar en modo alguno con lo que Velázquez podía hacer en aquellas fechas, y el soporte, cobre, es también totalmente ajeno al maestro. No obstante, es curioso que ambas pinturas parecen reflejar con absoluta fidelidad algo de lo que relatan los cronistas que, se ocuparon de la vida del veneradísimo trinitario.

Que se hicieron varios varios retratos del difunto lo asegura la Crónica General de la Orden de la Santísima Trinidad de Fr. Pedro López de Altuna que escribe en 1637, en fechas muy próximas a su muerte. Según este Cronista, una vez colocado el cadáver «en su ferétro, con su estola de sacerdote, cubierto de flores, con su bonete negro y borla blanca, insignia de maestro en Santa Teología, y sobre él escrito una AVE MARÍA, y al cuello echado su rosario blanco con su cinta azul, en una mano una imagen de Christo nuestro señor Crucificado, y en la otra una palma que significaba la laureada de Virgen... en esta postura estuvo toda la noche, y mandó su Magestad a dos pintores que cada uno de ellos sacase un retrato suyo y así lo hicieron, y el Prelado del Convento mandó hacer otro para fixarle en él».

Hubo pues tres retratos del venerable y así lo corrobora, años más tarde, el padre Fr. Francisco de Arcos en su «Vida del Venerable Siervo de Dios y firmísimo Capellán de la Reyna de los Angeles el R. P. M. Fr. Simón de Roxas» publicada en Madrid, en dos volúmenes, la Primera parte en 1670 y la Segunda en 1678. 

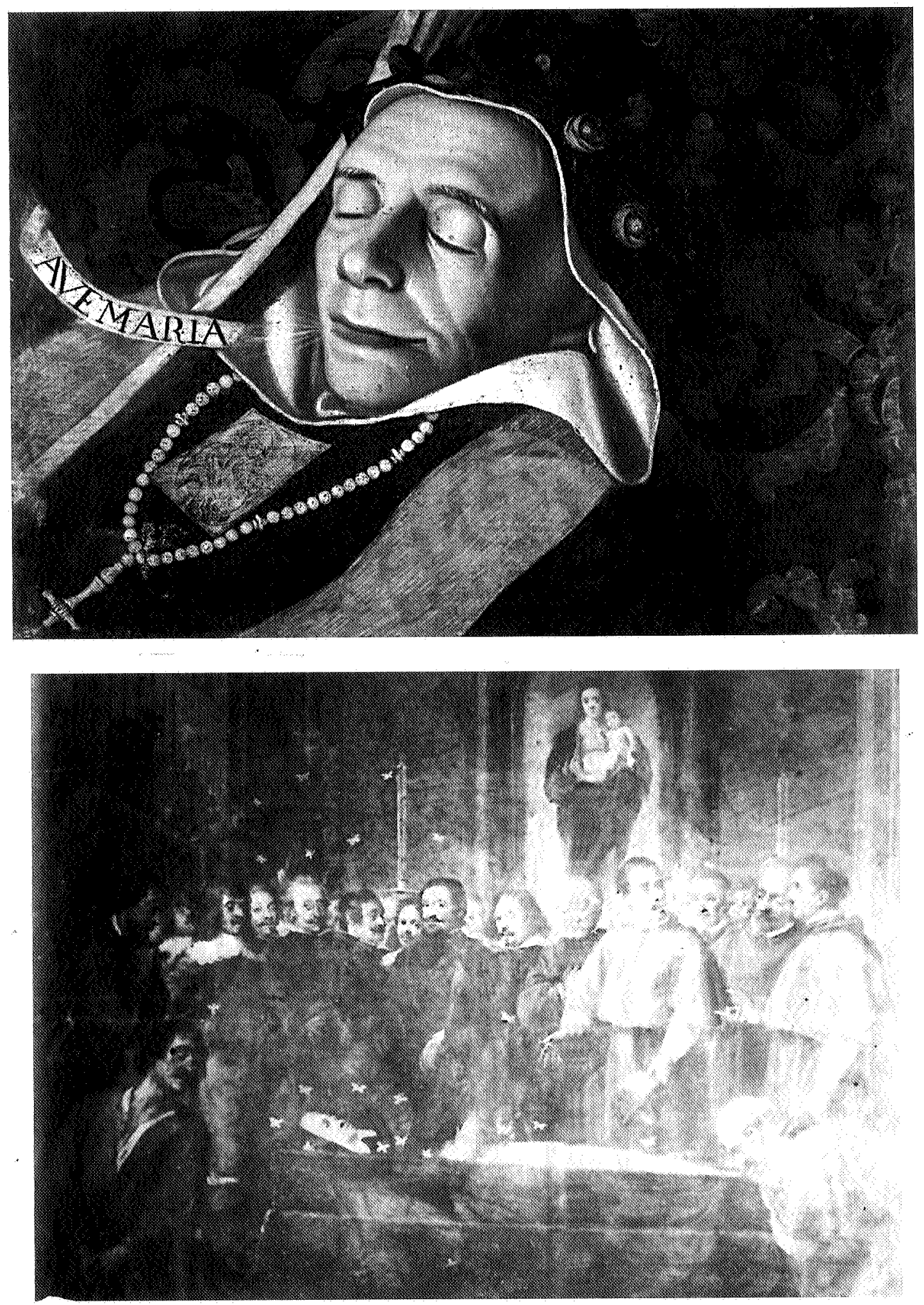

Figura 6. Anónimo: San Simón de Rojas, difunto. Madrid. Col. particular.

Figura 7. Anónimo: Exhumación de los restos de San Simón de Rojas. Antigua colección del Marqués de la Remisa. 
En esa segunda parte, al describir el entierro dice «Sobre la tumba se puso una Cruz pequeña y luces, a los pies, pendiente, un retrato del Siervo de Dios, como le hizo por Orden de la Reyna, su Soberana hija, después de haber expirado, el más primoroso artífice; tres se hicieron a un tiempo por tres grandes maestros, el mejor se llevó a su Magestad; éste quiso que se pusiera en el túmulo porque hallasen los desconsuelos de tantos en su propísima imagen algun consuelo» ${ }^{10}$.

El primero de los retratos que conozco parece reproducir fielmente la descripción primera, pues aparece en él la palma y el rosario al cuello. Al no verse las manos no puede afirmarse nada respecto a su posición.

Está visto desde arriba y del lado izquierdo del cadáver y parece insistirse mucho en la tela que debía envolver el túmulo. Su carácter es directo y atento ante todo a subrayar la expresión de beatitud del difunto.

El curioso cobre del Marqués de la Remisa, no puede relacionarse en absoluto con lo que las fuentes describen, pues corresponde a otro momento bien distinto y posterior al de la muerte del Santo. Se trata, en realidad, del momento de la apertura de su tumba para iniciar el proceso de beatificación.

López de Altuna lo relata con precisión. Después de enumerar todos los personajes que asistieron a la ceremonia, desde el cardenal Trejo y Paniagua, Obispos, nobles titulados y gentilhombres de Palacio, dice:

«Y todos juntos, y dos maestros de obras para q jurassen como no se auia abierto la parte donde estaua el cuerpo: y assi lo juraron; y rompiendo la pared facaron el ataud con gran cantidad de telarañas: y vno de quellos Principes dixo: Buen argumento es este de la verdad, que nadie ha llegado a el, pues las mesmas telarañas nos lo dizen: y tomandole en ombros los Perlados y señores que se hallaron mas cerca le pusieron encima de dos bufetes que estauan cubiertos con vn paño de brocado y quatro blandones de plata con sus achas a la quatro esquinas. El Prouincial q a la fazon era el Reuerendissimo $\mathrm{Pa}$ dre Maeftro Fr. Hortenfio Felix Parauicino Predicador de su Mageftad, dio la llaue del ataud al señor Cardenal Presidente, el qual la puso en manos de los juezes, para que la abriessen, y abriedola salio tan gran cantidad de mariposas blancas y al mismo instante se tocó la campana del Aue Maria sin saber quien la huuiesse tocado, salutacion con que ordinariamente recibia a todos. Los presentes repararon mucho en ello, y alauaron a Dios, y a su santissima Madre, q de todas maneras fauorecia a su sieruo. Hallòse el cuerpo entero sin faltarle cosa ninguna, y con mucha carne, particularmente en el pecho: Estaua tan blanco, y tratable la carne, y la garganta, como si estuuiera viuo, y el abito sin auerse apolillado, ni recibido ningun daño» 19 .

La aparición reciente de otro lienzo, de muy diferente carácter y calidad, creo que nos permite conocer, por fín, el original velazqueño.

Se trata de un lienzo de $1,01 \times 1,21$ que presenta al Santo tendido sobre un tablero o cama, vestido con el hábito de la orden trinitaria; la cabeza envuelta en la capucha o capillo, reposa sobre una blanca almohada. Sobre el pecho lleva un crucifijo pequeño de escultura y en las manos enlazadas sostiene un rosario, manteniendo erguida la pequeña cruz (Fig. 8).

10 Francisco de Arcos. Segunda Parte de la Vida del Venerable siervo de Dios. 1678.

$"$ López de Altuna. Crónica General de la Orden, pp. 571-572. 


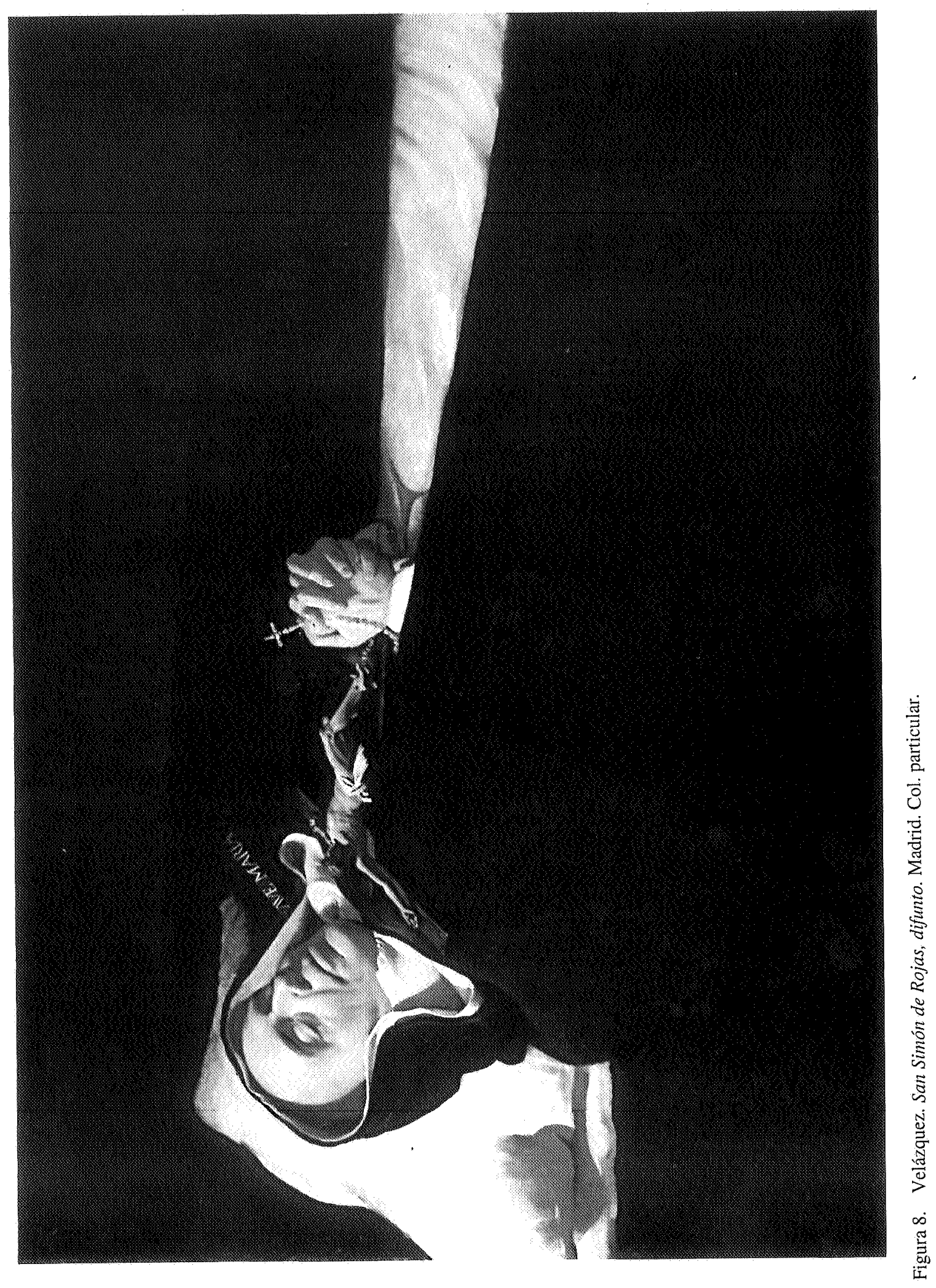


Se muestra, visto de arriba a abajo desde el lado derecho, casi paralelo a la superficie de la tela pero no aparecen los pies, truncada la figura a la altura de lo que podían ser los tobillos.

El fondo es oscuro y apenas se advierte la superficie oscura del plano sobre el cual descansa el cuerpo.

La iluminación es intensísima y procede de la izquierda, produciendo densas sombras en las partes opuestas al foco luminoso acentuando los valores escultóricos del rostro y manos del difunto y del hermoso crucificado que reposa sobre él. En la parte superior derecha del lienzó se lee «El R ${ }^{a}$ P.M. Fr. Simón D. Roxas» ${ }^{12}$.

La calidad de la pintura es soberbia y su examen atento, aún sin recurrir por ahora a exámenes de carácter físico-químico, muestra rasgos que pertenecen, inequivocámente a cuanto Velázquez hacía en 1624, recién llegado de Sevilla y aún en posesión de todos los recursos de su modo tenebrista de abordar el modelo.

La luz modela con absoluta precisión los volúmenes y se definen además, los contornos con unas sutiles pinceladas que dejan una especie de rebaba que se encuentra en todas las pinturas de Velázquez de los años anteriores al primer viaje a Italia.

Las obras de las que más cerca parece estar son, precisamente, el retrato de Góngora de Boston, obra de 1622, el primer retrato del Rey Felipe IV de Nueva York (1624) y el retrato del Conde Duque de Olivares de Sao Paulo (1624). Con este último tiene especialmente contacto el tratamiento de las manos, de color ligeramente tostado, y tocadas de luz de un modo muy pecuáliar, que se encuentra también en obras algo anteriores como el retrato de Sor Jerónima de la Fuente. El soberbio Crucificado sobre el pecho del cadáver está resuelto con una extraordinaria maestría y su paño de pureza se muestra muy semejante al del Cristo que sostiene en sus manos la misma Sor Jerónima, en la versión de la coleccî̋̂́n Fernández Araoz. El tratamiento de la blanca almohada, de tan prodigiosa tactilidad y tan maravillosamente resuèlta, con pinceladas largas y ligeramente onduladas, es absolutamente original y sólo se halla algo paralelo en el blanco mantel de la Cena de Emaus del Metropolitan Museum.

Puede sorprender, sin duda, que no se corresponda literalmente la disposición del difunto con las descripciones de los textos conocidos. No aparecen aquí ni la palma ni la estola, que si se ven en el otro, y tampoco el bonete y borla de doctor que, por otra parte tampoco se muestran en aquél. El rosario en vez de pender del cuello lo sostiene con las manos cruzadas, dejando visible la cruz, que resalta luminosa.

Velázquez, - pues estoy convencido de que de él se trata-, ha reducido la imagen a lo esencial, centrandose en el Venerable y mostrandolo con toda la sencilla inmediatez a que acostumbra, eliminando la más superficial parafernalia. El rostro, de serena placidez, tal como lo recogen todos los biógrafos, fue sin duda lo que interesó al pintor, atento siempre a lo más humano.

López de Altuna dice que «el rostro tenía tan alegre que parecía conservaba la alegria que en vida mostraba: tan hermoso como de un Angel, a quien en la pureza virginal fue semejante» y ciertamente el pintor ha acertado a darle una sensación de reposo sereno y bienaventurado, que contrasta con el del otro retrato en el que parece haver un cierto rictus.

Es curiosa la objetividad con que se describe en la sien derecha del Venerable una mancha que parece como una enfermedad de la piel o un grueso hematoma. Nada hay en los tex-

12 El lienzo procede de una noble casa titulada, y se consideraba en la familia como de Zurbarán. Es posible que sea el lienzo de Mayer aceptada como suyo y dice haberse exhibido en Sevilla en 1929, pero no he logrado identificarlo en los Catálogos impresos de aquella exposición. 
tos biográficos que aluda a esa llamativa mancha que, sin embargo Velázquez recoge con su precisa atención «al natural» dándonos una individualisima imagen, en la que se junta la realidad sin maquillaje y la necesaria severidad que la devoción reclamaba.

La identificación del retrato, cuya impresionante fuerza se impone al espectador desde su rotunda maestría técnica, creo que debe considerarse como una importantísima aportación al gran maestro en su centenario.

Respecto a los otros dos cuadros ya comentados, creo que el más fiel, podría —con cierta probabilidad-, atribuirse a Bartolomé González que en 1624 era también pintor del Rey y especialista en retratos. Parece lógico que los pintores que S.M. enviara fuesen precisamente los retratistas, y no debe olvidarse que Velázquez ocupó la plaza de Rodrigo de Villandrando y era en esa fecha conocido sobre todo como «retratador».

El cobre con la escena de la apertura del sarcófago, es de más dificil atribución y creo que debe corresponder a fecha mucho mas tardía, alejada ya la memoria directa del hecho. Es curioso que aparezca entre los caballeros, perfectamente reconocible, el Conde Duque de Olivares que no aparece en la relación de Lopez de Altuna. Es posible, incluso, que se trate de pintura tardía, hecha a la vista del relàto y por completo ajena a cuanto se pintaba en 1624.

Ya conocida por su comparecencia en subasta pública en Nueva York y por una tensa polémica recogida en la prensa diaria respecto a su atribución, dando voz a quienes no tienen, en modo alguno, autoridad ni conocimientos, es la figura de una delicada Santa alfarera considerada Santa Rufina que reapareció en el mercado neoyorkino con un cuidadoso y bien documentado informe firmado por el Dr. Peter Cherry que rastrea con minuciosidad la historia externa del lienzo ${ }^{13}$, identificándolo, seguramente con toda razón, con la pintura de «Santa Rufina, de medio cuerpo con palma y media de alto y dos tercios y dos dedos de ancho» que se recoge entre las obras que pertenecieron a D. Luis Méndez de Haro, Marqués de Helich y del Carpio, sobrino y sucesor del Conde Duque de Olivares como privado del Rey Felipe.IV, en los documentos aportados a la testamentaria de la Duquesa de Alba en 1802 con motivo del pleito entablado al no tener ésta herederos directos. (Fig. 9)

Sorprende un tanto que fuera de esa mención relativamente tardía, no se haya encontrado hasta ahora noticia del lienzo en otros inventarios de la Casa del Carpio o de Alba, pero no parece que pueda dudarse de la identificación, a la vista de la descripción y de las dimensiones virtualmente idénticas con el lienzo ahora presentado que, hasta relacionarlo con la citada mención documental, se llamó Santa Justa.

La historia externa del lienzo se ha podido rastrear a partir de 1868 en que aparece en la Galeria del Conde de Dudley que lo presenta en la Exposición de Arte de Leeds atribuyéndolo a Murillo. No debe sorprender el cambio de atribución. Velázquez era conocido en el siglo XIX principalmente como retratista y la figura de una joven, casi una niña, de delicadeza extrema, no encajaba en su imagen y sin embargo correspondia perfectamente a lo que el público británico había configurado para Murillo, estimádisimo de todos y objeto de altas valoraciones económicas. Llamarla Santa Justa parecería lógico, al tratarse de la primera de las Santas Hermanas que se nombran habitualmente juntas y en ese orden.

Siempre como Murillo permanece en la colección Dudley hasta que se pone en venta en Christi'es de Londres en 1925, pasando entonces a manos de un conocido galerista (LeggatBrothers) y luego por distintos propietarios y Galerias. En 1948 fue subastado de nuevo en

${ }^{13}$ Christie's Nueva York. Spanish Old Master Paintings, 29 eneroo 1999, lote n. ${ }^{\circ} 206$.

14 Toda esta historia externa se recoge ya en el citado Catálogo de la subasta. 


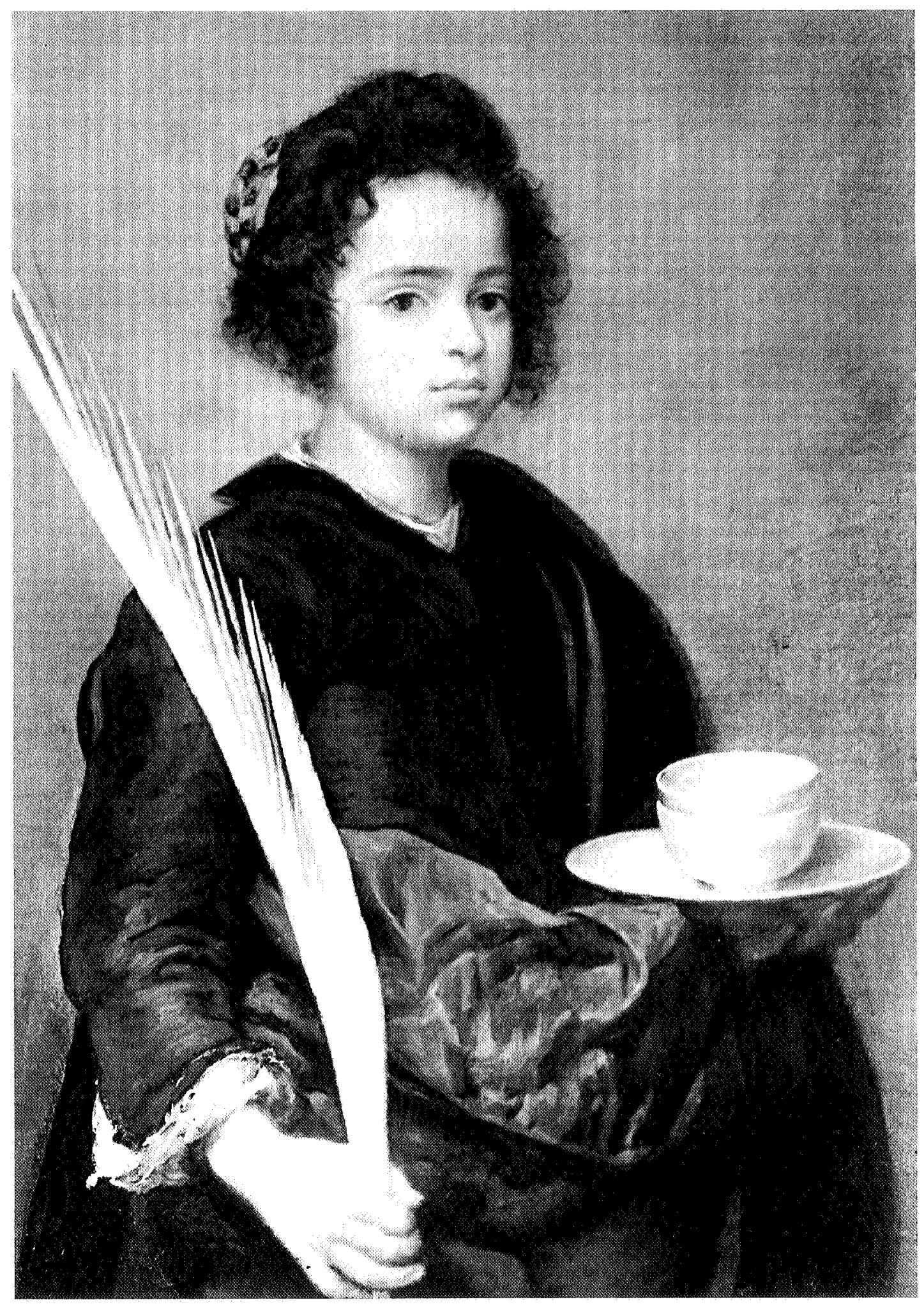

Figura 9. Velázquez. Santa Rufina. Col. particular. 
Nueva York, en la Galeria Parke Bernet pasando a manos de un coleccionista argentino que la exhibió en Exposición pública en Buenos Aires en 1951, siendo luego adquirida por una familia brasileña que lo ofreció en venta a Christi'es en febrero de 1999, ya con atribución a Velázquez y recuperando la identificación como Santa Rufina.

Pero es curioso que en 1930, cuando todos lo consideraban de Murillo, Angustias L. Mayer advirtió, en una breve nota ${ }^{15}$ la imposibilidad de que fuese obra de ese maestro y apuntó, sin dudarlo, el nombre de Juan Bautista Martínez del Mazo, haciendolo asi regresar a la órbita de Velázquez aunque en una dirección equivocada. Mazo era entonces - y aún ahora - un cómodo recurso para obras «velazqueñas», más o menos problemáticas. Pero en este caso, quedó corta la propuesta, que al parecer no tuvo repercusión alguna, pues el lienzo continuó, hasta fecha bien reciente, considerándose de Murillo. Todavía en 1931 se reproducía como tal en el The International Studio, siendo recogida en sucesivas ventas y exposiciones como ya hemos dicho. Solo Angulo, sin conocerlo, rechazó otra vez la atribución murillesca limitándose a recoger lo dicho por Mayer ${ }^{16}$.

Paralelamente, la noticia de la existencia de una Santa Rufina de Velázquez que fue de los Haro y Guzmán se ha ido repitiendo como obra perdida en todos los Catálogos y Monografías del gran maestro ${ }^{17}$ sin que se haya advertido la perfecta correspondencia entre la descripción del Inventario y el lienzo tantas veces reproducidoo como Murillo.

Respecto a esa atribución a Murillo, poco hay que añadir a lo dicho por Mayer. Nada hay en el estilo o la técnica del lienzo que pueda asimilarse al pintor de las Inmaculadas y tampoco el modelo humano se relaciona con los empleados, una y otra vez, por este artista.

La pintura, por otra parte, corresponde sin duda a un momento estilístico muy anterior a los años de actividad de Murillo, pudiendo situarse hacia 1630 aproxidamente.

La atribución a Mazo propuesta por Mayer, tampoco parece aceptable. Aunque la personalidad del yerno de Velázquez continúa siendo un tanto huidiza, y es poco lo que con entera seguridad puede considerarse suyo - y por lo tanto servir de pieza de comparación para nuevas atribuciones-, parece siempre deudor del Velázquez más libre y deshecho, llevando la peculiar técnica del maestro a un punto de deshacimiento e inmaterialidad extremo. Por otra parte parece que posee una especial manera de tratar las manos de sus personajes (Doña $M a-$ riana de Austria, Londres, National Gallery), alargando los dedos puntiagudos hasta un extremo casi inverosímil. Nada hay de ello en este lienzo, cuya materia traduce una sólida corporeidad, valiéndose de una pincelada libre, pero bien atenta a definir los volúmenes, y donde la mano del primer término se muestra bien gordezuela.

Aún sin atender a la historia del cuadro y a su, para mí evidente, identificación con el lienzo que fué de Don Luis de Haro, los paralelismos más claros se establecen con obras de Velázquez en torno al momento previo al primer viaje a Italia, es decir hacia 1629, cuando, aunque el atento estudio de los lienzos de la colección real había ya liberado su paleta de tenebrismos, se mantenía todavía algo de su formación sevillana.

El modelo infantil, por otra parte, presenta ciertas familiaridades con los modelos de los dos conocidos dibujos de muchachas de la Biblioteca Nacional, y no resulta tampoco difícil advertir ciertas semejanzas entre esta delicada muchachita, un tanto rústica, y la Virgen y sus santas acompañantes en la Imposición de la casulla a San Ildefonso del Ayuntamiento de Sevilla, obra, como es sabido, fechable hacia 1623.

is Mayer, A.L. El Arte español en el Extranjero. «Tres culdros interesantes desconocidos». Arte Español, 1930 , p. 118

${ }_{16}$ Angulo Iñiguez, Diego. Murillo. Su vida, su arte, su obra. Madrid, 1981, Vol. II n. ${ }^{\circ} 518$, n. $^{0} 2258$.

17 Véase, por ejemplo, López Rey. Velázquez. A Catalogue. 1963, p. 137, n. 51. 
Sin embargo, creo que los paralelos más directos en cuanto a técnica y color, hay que establecerlos con el retrato de Doña María, reina de Hungría,mucho tiempo creído pintado en Nápoles en 1630, pero parece, tras las investigaciones de E. Harris y J. Elliot, hecho en Madrid el año anterior.

Se han señalado también semajanzas evidentes con la figura de la Sibila del Prado, considerada retrato de la esposa de Velázquez, pensando que pudiera ser obra de los primeros años treinta, recién regresado de Italia.

Creo, sin embargo, que el emplazamiento cronológico mas convincente es inmediatamente anterior al viaje y no es imposible que se pintase para alguno de los protectores sevillanos que le ayudaron a triunfar en la Corte, quizás el propio Conde Duque, en cuya familia aparece luego, como se ha visto.

Como es bien sabido, la Santa Alfarera se suele representar emparejada con su hermana Justa, bien en un solo lienzo, como los de Miguel de Esquivel (h. 1615-1620) o el de Goya (1819) en la Catedral de Sevilla, o en dos lienzos compañeros, como en los de Murillo de Fort Worth.

Quizás este lienzo tuviese una pareja con la otra Santa hermana, pero nada podemos afirmar ahora. Es curioso que, como hemos dicho, en toda la historia conocida del cuadro hasta fecha reciente se le considerase Santa Jüsta.

Y puedo añadir más datos a la historia decimonónica del lienzo, pues las menciones a una Santa Justa «de Don Diego Velázquez, alto tres cuartas y media, ancho tres» que aparece en la colección de D. Francisco Casado de Torres, tasada en 5000 reales por D. Juan de Rivera ${ }^{18}$ y a otra Santa Justa «de alto 3 y media cuartas y de ancho 2 y media» valorada en 10.000 reales por José de Madrazo en 1844 entre los cuadros pertenecientes a D. Celestino García Fernández ${ }^{19}$ se refieren sin duda a nuestro lienzo y ayudan a cubrir el vacio entre la mención de comienzos de siglo, y su aparición en Inglaterra en 1868.

$=0$

Que se trata del mismo lienzo, a pesar de la ligera diferencia de dimensiones, lo asegura el hecho de que en ambas colecciones se citan también otras obras atribuidas a Velázquez, un Vulcano, un perro, un gato y una Ciega.

Como es bien sabido las colecciones isabelinas se formaron y dispersaron una y otra vez en estos años y fueron los ingleses los beneficiados del zafarrancho.

En cuanto a la atribución a Velázquez, negada o puesta en duda por algunos historiadores de cierto prestigio y por artistas ayunos de conocimientos histórico-artísticos, no parece discutible a la luz, no solo de lo que el lienzo muestra a la vista, sino tambien a traves de los estudios radiológicos y técnicos que ya se dieron a conocer en ocasión de la subasta en la que obtuvo crecido precio. Técnica preparación y «ductus» son con toda evidencia los del maestro en un período de transformación de su técnica sevillana al contacto con lo que Madrid y sus colecciones le ofrecía, lo que explica la vacilación en situarlo antes o después del viaje romano de 1630-1631. Si bien es cierto que presenta afinidades con alguno de los retratos hechos a su regreso, tal como ha señalado Peter Cherry, si se le compara con las Tentacionés de Santo Tomás de Orihuela, pintado en 1631-1632, se advierte una mayor contención, un dibujo más prieto y una mayor densidad de pasta en pormenores como la soberbia palma y las tazas blancas, que evocan todavía, la maravillosa materia de los bodegones sevillanos.

El lienzo está siendo en la actualidad sometido a una limpieza que elimine barnices y repintes que ocultan, sin duda, viejos daños y haga brillar, aún más, sus maravillosas calidades.

18 Biblioteca Nacional. Manuscritos. n. ${ }^{\circ} 18650$, n. $^{\circ} 40$.

19 Debo esta noticia a Don Álvaro Piedra. Los lienzos atribuidos a Velázquez en ambas colecciones ofrecen unas pistas que habrán de ser recorridas por otros. La Ciega, «de alto media vara, ancho una tercia» es sin duda el lienzo que se conserva en la Galeria Nacional de Poznan (Polonia), de dimensiones, 0,46 x 0,35 y procede de la colección Raczinsky, adquirido precisamente en Madrid en 1854. Veáse en el Catálogo Malarstwo Hiszpanskii XIX-XVIII Wiwku w Zbiorack Polskich, Poznan, 1967, n. ${ }^{\circ} 40$. 
Con menos rotundidad pero con íntimo convencimiento de su calidad es preciso referirse a una nueva versión excelente, del retrato de Felipe IV viejo, que se relaciona muy directamente con las versiones de Museo del Prado y de la National Gallery de Londres. Procede de la colección del Infante Don Luis, hermano de Carlos III, de su palacio de Boadilla y conserva bien visible el . $^{\circ} 20$ del inventario y el monograma que llevan todas las pinturas de la colección del Infante (Figs. 10 y 11).

La presencia de una cadena, quizás para que de ella penda el Toisón, le relaciona más directamente con el ejemplar de Londres que, como es sabido, no todos los críticos lo consideran autógrafo. El ejemplar que ahora se da a conocer resulta de una intensidad expresiva y de una fluyente calidad técnica que obliga a considerarlo autógrafo.

El tratamiento del cuello almidonado, resuelto con pinceladas largas y sueltas, con un ligero reborde o rebaba, la sedosa tactilidad del cabello y la expresión de melancólico alejamiento, más humana y tierna que en las otras versiones consideradas autógrafas, hacen del lienzo una importante recuperación.

A su lado tanto la del Prado, que se viene fechando hacia 1655, pues esa es la fecha del grabado de Pedro de Villafranca que lo reproduce, como la de Londres que posiblemente será algo posterior, pues otra estampa de Villafranca, que parece reproducirla, se fecha en 1657, presentan al monarca algo más grueso y con las mejillas y los ojos más flácidos y abotargados.

Esta hermosa cabeza será un poco anterior, quizás hacia 1651-1654 recién vuelto el pintor de Italia. Su tensa humanidad responde, mejor que ningún otro, a la expresión de Diaz del Valle, cuando al referirse a un retrato del rey que acababa de pintar Velázquez y que él admiraba por encima de cualquier otro de los conservados en Palacio, dice que «tenía mucha alma en carne viva».

La radiografías del lienzo muestran, con toda evidencia la identidad de técnica del cuadro con otras obras del maestro. Los toques sueltos y libres del pincel en zonas inexpresivas de la tela, cubiertas luego, son los característicos restregones para limpiar el exceso de pasta en el pincel, que tanto se han señalado en su obra y la extraordinaria seguridad de los toques blancos, de mayor intensidad radiográfica, subrayan aún más su fuerza.

La comparación con cualquiera de las múltiples copias conocidas que López Rey reproduce, pone de manifiesto la absoluta superioridad de la que presentamos.

Y a Velázquez creo que debe reintegrarse también un sorprendente Retrato de Caballero (Fig. 11) que ya en 1924 se dió a conocer como «atribuido» al maestro en la colección de los Vizcondes de Roda, pero que no ha sido después tomado en consideración ${ }^{20}$. Reaparecido recientemente, su detenido estudio obliga a reconsiderar la vieja atribución. Es posible que se trate de un fragmento pues la sola cabeza, tal como aquí aparece no es habitual y es evidente que, por la parte lateral derecha,concluye de modo abrupto e ilógico. El rostro, de una profundidad de mirada absolutamente fascinante, está modelado con un rigor formal y una pincelada analítica que sólo halla paralelo en las obras juveniles del maestro, pudiendose situar, idealmente, entre el creido retrato de Pacheco del Prado ${ }^{21}$ y el Góngora de Bostón ${ }^{22}$. El modelo de la oreja, el tratamiento de las cejas y los surcos del entrecejo, asi como el modo

20 Peñuelas, J. Visita a la colección de los Excmos. Sres. Vizcondes de Roda. Boletín de la Sociedad Española de Excursiones, 1924, pp. 128-130.

${ }^{21}$ Véase Catálogo de la citada Exposición de Sevilla de 1999, n. ${ }^{\circ} 95$.

22 Idem, n. ${ }^{\circ} 100$. 

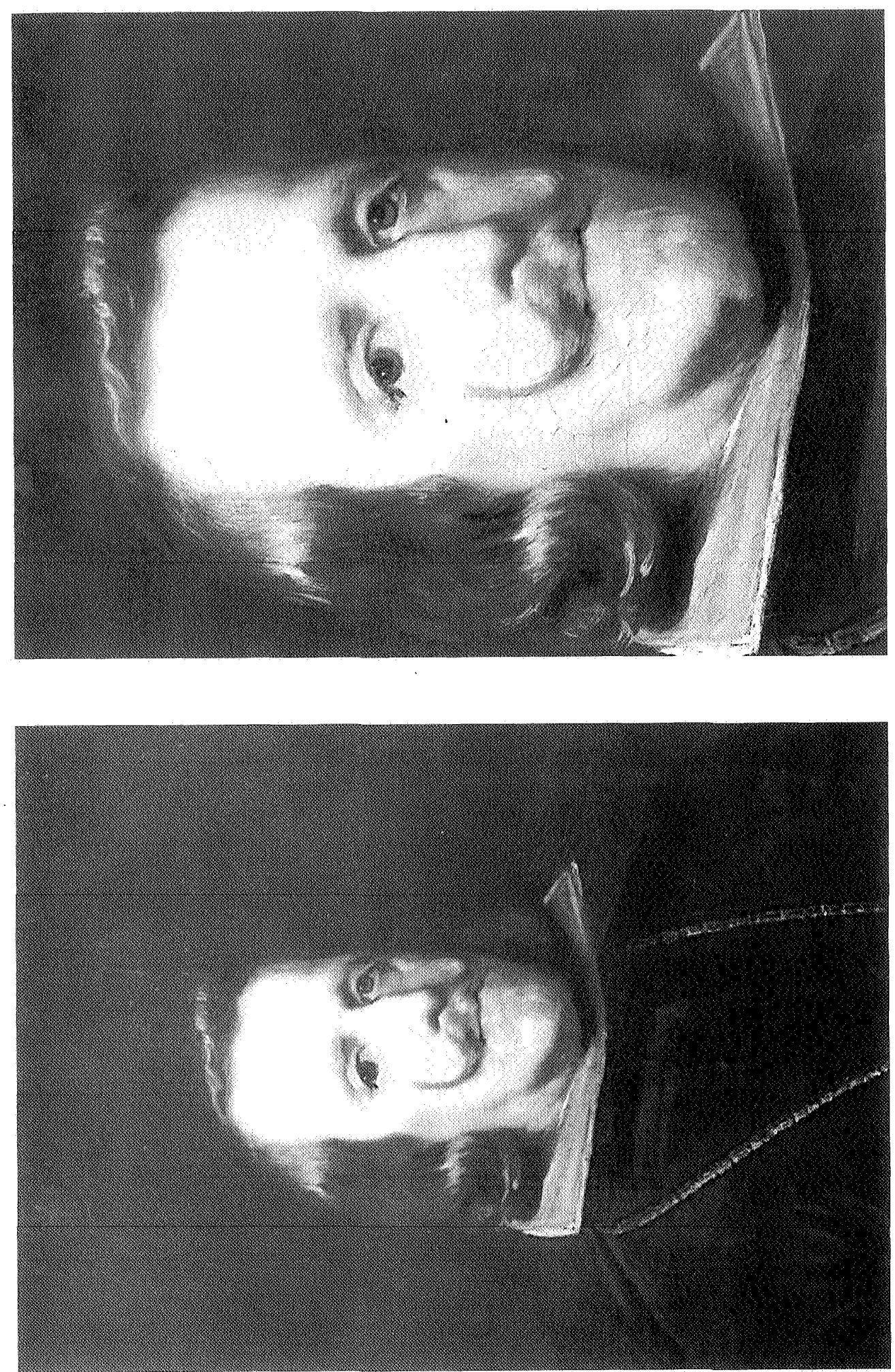

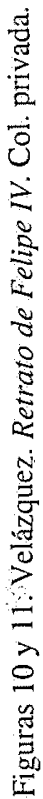


de resolver la nariz con una leve pincelada clara longitudinal, enlaza este retrato con los citados. Sólo sorprende, quizás, el tratamiento del rizado cuello de puntas de encaje en el que se encaja la cabeza de modo un tanto extraño. Si el retrato, como parece, debe situarse hacia 1622-1623, resulta un tanto chocante la moda que, al hilo de diversas pragmáticas contra el lujo, había recortado y simplificado notablemente los excesos de los cuellos de la época de Felipe III. Pero no puede olvidarse que esa moda rica, se mantuvo en ciertas zonas europeas en contacto con lo español, especialmente en Génova y en Flandes, como atestiguan algunos retratos de Van Dyck, de la década de los 20 precisamente. Cabría pensar si el Caballero aquí representado, de tan fuerte expresión y rotundo carácter, no sería algun noble no español, presente en la Corte a la llegada del pintor. De la atribución a Velázquez creo que no debe haber duda, pues incluso, los encajes de tan minuciosa traza, están tocados con un sentido de la luz y una capacidad de vibración que sólo una mano magistral podría lograrlos. Basta comparar con el modo, seco y mecánico con que los traza Bartolomé González, para acreditar la diferencia.

Y como contrapartida a estos incrementos del Catálogo, más o menos riguroso, del artista, creo que es esta la sede adecuada para razonar mi rechazo de la atribución a Velázquez ${ }^{23}$ de una hermosa Inmaculada que se ofreció también en venta en Sotheby's en julio de 1994, desplegando, a su respecto, una considerable publicidad, apoyada en las semejanzas que ofrecía con la indudable Inmaculada de Velázquez en el National Gallery de Londres, pero que tuve ocasión de afirmar en varias ocasiones que se trataba de obra juvenil de Alonso Cano (Fig. 12).

Para defender la atribución a Velázquez se aludía a la semejanza de técnica entre ambas imágenes que, desde luego era notable, pero que puede explicarse sin dificultad alguna teniendo en cuenta que ambos artistas se han formado en el mismo taller, han intercambiado sin duda experiencias y el joven Cano hubo de admirar sin ninguna duda al condiscípulo más veterano e imitar con fidelidad sus procedimientos. La Inmaculada de Velázquez suele fecharse hacia 1619. Cano ingresa en el taller de Pacheco en 1616, coincidiendo allí en los últimos tiempos con la formación de Velázquez, que seguramente realizaba ya algunas obras personales. Que el joven imitase o aprovechase las experiencias del mayor, es absolutamente lógico. Pero al margen de las coincidencias técnicas, la diferencia de concepción y espíritu entre ambas imágenes es muy fuerte. La Inmaculada velazqueña presenta una recatada actitud de elegante y sereno contraposto, con las manos juntas sobre el pecho, ligeramente inclinadas hacia la izquierda, mientras la delicada cabeza se vuelve hacia la derecha. La túnica, de un bello tono violáceo, cae verticalmente y marca dos enérgicos pliegues verticales que subrayan el elegante aplomo de la imagen toda. La rodilla derecha avanza un tanto y marca el relieve escultural del cuerpo. El manto flota al aire en el lado derecho y apenas se recoge a la izquierda sobre el brazo, dejando bien visible la ancha manga de la túnica.

La Inmaculada, erróneamente atribuida, se presenta frontal, con las manos juntas perpendiculares al pecho. La cabeza erguida y la mirada perdida y un tanto inexpresiva. Contrasta con la delicadeza y recato con que la de Velázquez cierra los párpados, siguiendo en ello el modelo de Pacheco.

La silueta de la imagen es decididamente fusiforme. La túnica, la tonalidad violeta más densa que la del otro, presenta pliegues hondos, ciertamente próximos a los de Velázquez, pero de aristas más cortantes y definidas, como de escultor. El manto se ciñe bajo el brazo derecho y se pliega sobre el izquierdo creando un ensanchamiento de la silueta por la parte central, de cintura y caderas, y se repliega hacia los pies, apretándose primero y abriéndose luego de modo muy particular, para ceñir la transparente esfera de la luna en que se asienta la Virgen.

23 Sotheby's Londres, 6 de julio de 1994, lote 64. La subasta ofreció mucha expectación y se publicó incluso una separata del Catálogo dedicada al lienzo, que por fin, no se vendió. 


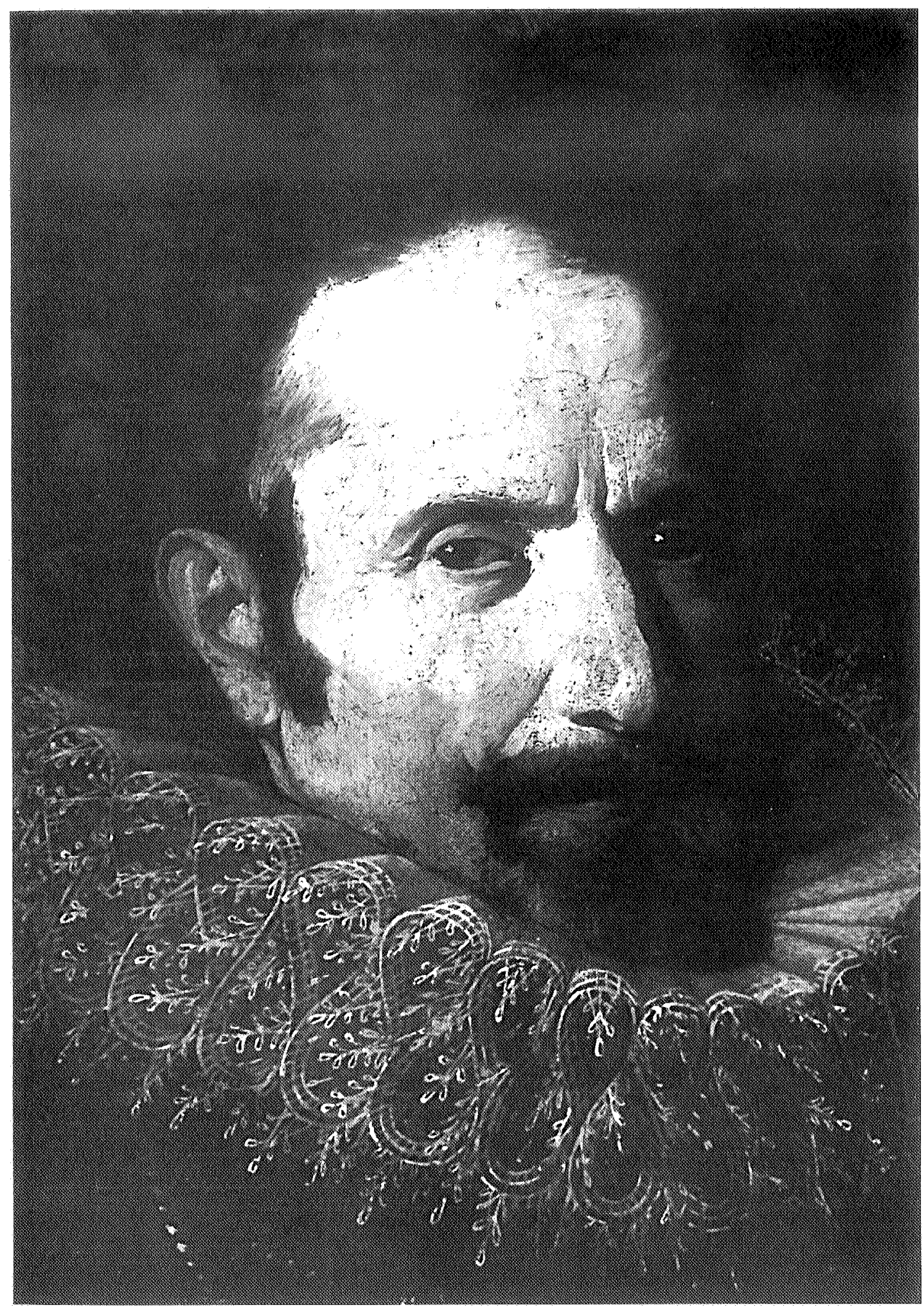

Figura 12. Velázquez. Retrato de Caballero. Col. particular. 


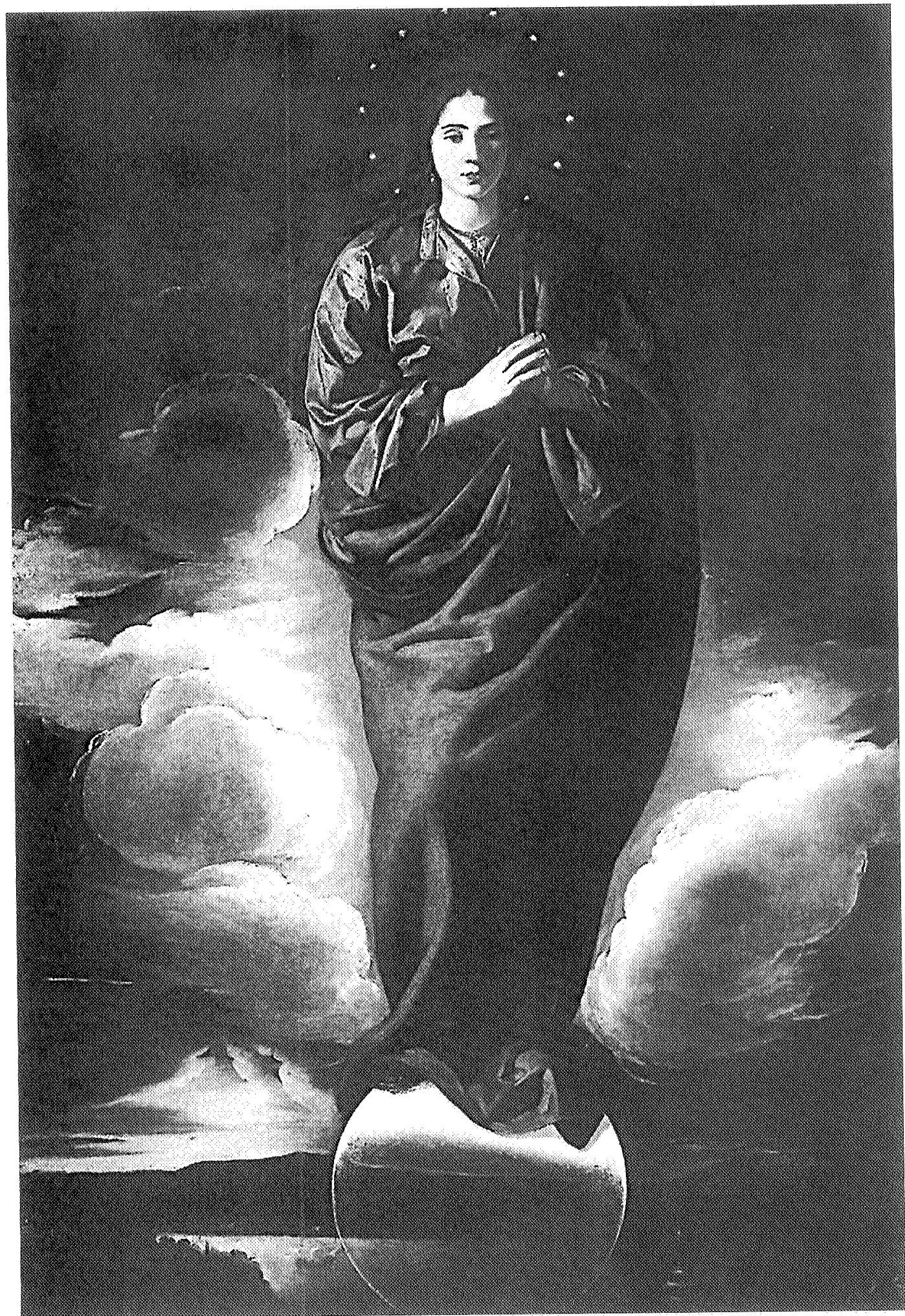

Figura 13. Alonso Cano. Inmaculada Concepción. Col. particular. 

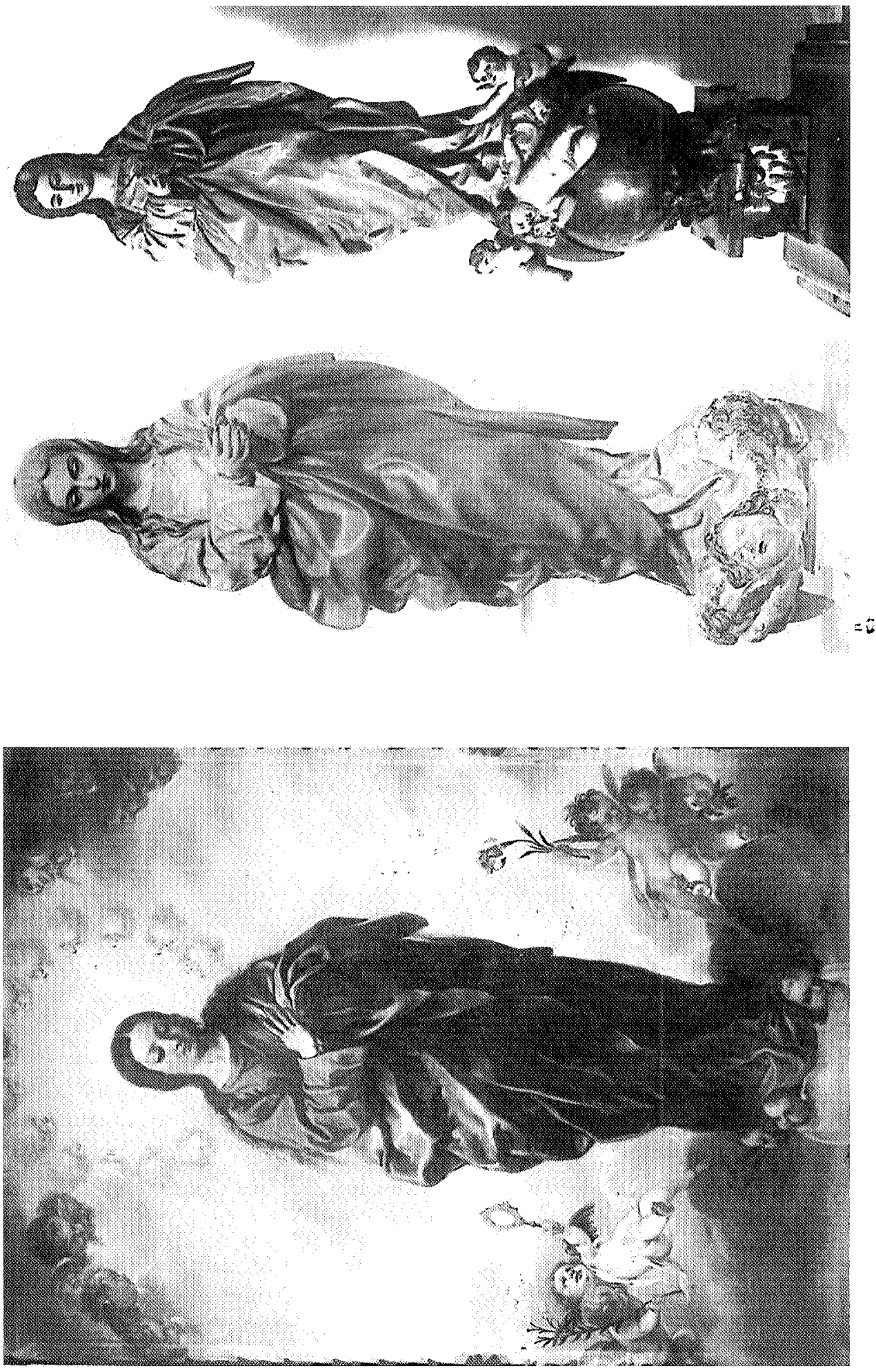

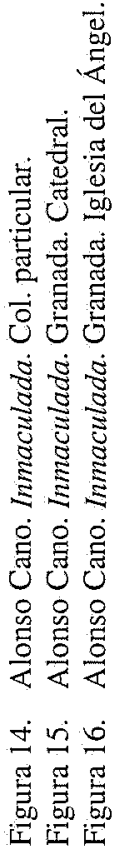


Esta silueta y estas características son las que Alonso Cano mantiene a lo largo de toda su carrera para representar la Inmaculada. Ese perfil fusiforme ha sido repetidamente señalado como característica suya, y se encuentra tanto en las pinturas (Inmaculadas del Marqués de Cartagena, y del Oratorio de la Catedral, ambas en Granada, o en otros de propiedad particular) e incluso en imágenes de Santos (San José de la colección Masaveu), como en esculturas (La Inmaculada de la Catedral de Granada o la de la Iglesia del Angel, quizás de taller, pero que responde perfectamente a su esquema (Figs. 13, 14 y 15).

Una relativa inexpresividad del rostro, que es perfectamente compatible con una notable delicadeza en el modelo, y la forma gordezuela de las manos las encontramos en toda la producción posterior de Cano, que sin duda creó el modelo en el taller de su maestro a la vista tanto de las realizaciones del viejo Pacheco, como sorprendido por la intensidad de realidad viva y tierna que su condiscípulo genial había ya modelado.

Algunas otras obras atribuidas en los últimos años a Velázquez, requerirían revisión detenida. El Catálogo de José Gudiol, especialmente, incorporó algunas obras que no resisten la crítica rigurosa. Pero en esta ocasión centenaria basta quizás, con incitar al mejor conocimiento del maestro y a mantener abierta la — por otra parte difícil— posibilidad de enriquecimiento de su producción conocida con novedades que respondan a su maestría. 